\title{
Conversación con Estuardo Núñez ${ }^{1}$
}

\author{
Carlos García-Bedoya M. \\ Departamento Académico de Literatura
}

Doctor; a usted le tocó vivir una época do caubio en los estudios literarios, en la crítica literaria ¿Cómo vió esa experiencia desde el Perí en sus años juveniles, y cómo participó en ella?

Hacia el año 30, la crítica literaria estaba todavía en la etapa del historicismo, todo se juzgaba a través de la historia del devenir literario, incluso las figuras literarias estaban muy vinculadás con elampresiondsmogindividual de los comentaristas. Yo fui, digamosj testigede excepqión del cambio de criterio imperante en esa época. Al comienzo del año 27, por ejemplo, ya se operaron algunas transformaciones fundamentales en la crítica española incluso. Algunos miembros de la generación del 27 en España se preocuparon de cambiar el rumbo de la crítica española, que había sido más o menos la que habíamos seguido en América Latina. Entonces surgen, por ejemplo, los primeros trabajos de Amado Alonso, de Dámaso Alonso, que pertenecen a esa generación, trabajos que enfocan de distinta manera los autores clásicos y modernos españoles. Coincidió esto con la celebración del cuarto centenario de Luis de Góngora en 1927, cuando se comenzó a estudiar la poesía de Góngora de una forma distinta de

Esta conversación (pues no fue propiamente una entrevista) tuvo lugar a fines de 1990. Se trató de un diálogo amplio sobre los estudios literarios en el Perú. en función de las vivencias de uno de sus exponentes más destacados, el doctor Estuardo Núñez. Las partes inicial y final del diálogo no fueron registradas, pero lo que se incluye aquí constituye lo central de la conversación.

Letras (Lima), 95-96: 225-236, 1998. 
como se le había venido estudiando anteriormente y se descubrieron los valores intrínsecos de los poemas de Góngora que habían permanecido un poco marginados. Se hicieron esas primeras ediciones sobre Góngora que nosotros leíamos aquí gracias a las publicaciones de la Revista de Occidente.

\section{¿Llegaban acá rápidamente?}

Llegaron al Perú rápidamente y se apreciaron mucho, sobre todo por la gente joven que vio en esos estudios unas nuevas posibilidades. Yo mismo pude darme cuenta de dónde partían estas nuevas tendencias de la crítica española. Ubiqué fácilmente que partían de fuentes alemanas que después se fueron revelando poco a poco, entonces no se habían revelado. Yo me preocupé de buscar esas fuentes alemanas e inglesas, de informarme de bibliografía pertinente. Fue así como emprendí la tarea de estudiar a José María Eguren, con un nuevo criterio, con el criterio de analizar los elementos particulares de la poesía de Eguren y descubrir una serie de cosas que no se habían dicho hasta ese momento. Cuando Mariátegui el ã̃o 28 decide lanzar un número de homenaje a Eguren en su revista Amauta, me invito a mí, para que yo hiciera un estudio de la poesía de Eguren. Entonces yo me salí de los cartabones con los que se había estudiado a Eguren hasta ese momento y presenté una colaboración para Amauta que estudiaba por ejemplo el tratamiento de los colores.

¿En ese tiempo usted todarigerg estudiante?

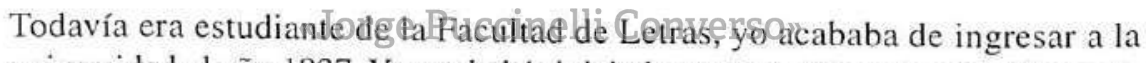
universidad el año 1927. Yo me había iniciado como colaborador del Mercurio Peruano desde el año 26. En 1927 yo colaboraba también en Amauta, porque Eguren, a quien conocí aquí en Barranco con Martín Adán, nos había llevado a la casa de Mariátegui para conocerlo, para hacernos conocidos de Mariátegui, porque Mariátegui quería tener contacto con gente nueva, de las nuevas generaciones, le gustaban mucho el contacto con los jóvenes. Formamos parte de la tertulia de Mariátegui y así surgió la cuestión de Eguren y el número de homenaje a Eguren. Entonces yo escribí un artículo que se llamó «La estética del color en la poesía de Eguren». Eso fue el germen de un libro que poco tiempo después resultó mi tesis para graduarme de Doctor en la Facultad de Letras de San Marcos, de la cual un capítulo fue ése, el estudio del color en la poesía de Eguren. Esto naturalmente significaba un rompimiento con esa crítica meramente impresionista o historicista que había dominado anteriormente, y el planteamiento de una nueva forma de hacer crítica, estudiando detenidamente los fenómenos intrínsecos del estilo del escritor. Lo mismo que se hacía en España 
respecto a poesía del Siglo de Oro, como la poesía de Góngora, yo lo hice aquí por primera vez con una figura de la literatura peruana. El asunto fue muy bien recibido por la gente que ya tenía noción de estas innovaciones. Recuerdo que a Mariátegui le gustó mucho, no había visto nada semejante en la apreciación sobre Eguren. Gustó esto mucho también a un crítico, a un hombre de un gran sentido de la investigación en la literatura nueva y de gran inquietud, que había sacado una revista muy importante para la nueva generación, fue Adalberto Varallanos, un joven que se murió tuberculoso poco tiempo después, pero que realmente era una gran promesa, y que pudo haber sido una gran figura de la crítica literaria. El me felicitó y me alentó mucho y me dijo que ese trabajo iniciaba una nueva etapa aquí en el Perú y que persistiera, y que ése era el nuevo rumbo de la crítica. Eso me animó mucho y luego seguí trabajando en otros aspectos de la poesía de Eguren. Así surgió mi libro sobre Eguren de 1932, que tuvo una versión posterior de 1965, además de la edición norteamericana de la Universidad de Columbia de 1960. La publicación de mi libro en 1932, produjo reacciones muy curiosas, porque hubo gentes a quienes le chocaba el método. Sostenian que la obra de un poeta no debía tratarse así, que no debía examinarse así, porque esto rompía el encanto de la poesía. No se puede aplicar razonamientos a la poesía, considerabap que en esa forma se rompe el encanto de la poesía y a la poesía simplentente debía juzgársela en un plano de carácter impresionista, superficial, meramente discursivo, de apreciaciones individuales, pero no con un criteriomás elaborado, más rịguroso para juzgar la poesía. Yo estaba en ese entonces muy penetrado ya de las nuevas corrientes que venían de Alemania e Inglaterra, deląestiustica, edel kNew Criticism", de lo que se llamaba en Alemania, se sigue llamando todavía, la literaturwissenschaft, o sea la ciencia de la literatura. Y yo vi con satisfacción que en otros lugares de América se estaba operando de la misma manera. Un crítico chileno muy renombrado, que había estudiado en Alemania, Roberto Mesa Fuentes, publicó, al mismo tiempo que yo, un libro sobre la poesía del poeta uruguayo Julio Herrera y Reissig. Este autor fue estudiado por ese crítico chileno, coincidiendo en lo mismo que yo, porque manejábamos las mismas fuentes y métodos. Y así se fue generalizando esto que se llamó la estilística, los estudios estilísticos, como por ejemplo también el estudio de Amado Alonso sobre la poesía de Neruda. Esto lo ha reconocido después Alberto Escobar, que ha estudiado el proceso de la prosa en el Perú. Esa fue una etapa importante del proceso de la crítica en el país, después ya se ha impuesto como una manera fundamental para estudiar una poesía o para estudiar una obra literaria en general, pero en ese momento fue una novedad. 


\section{Doctor ¿usted ha seguido trabajando en el campo de la estilística?}

No he seguido trabajando tanto como entonces, porque a mí me han tentado siempre los terrenos vírgenes, y así como esto de la estilística fue un terreno virgen en que yo entré un poco con intuición, más que con un conocimiento profundo de la estilística, que se pudo apreciar después. Yo he perseguido siempre entrar en materias que no habían sido trabajadas anteriormente. Entonces, después me orienté más bien por la literatura comparada. En eso me ayudaba un poco el conocimiento de idiomas, el alemán, el inglés, y después otros idiomas, el francés que fui estudiando a mi manera, un poco así como aficionado a los idiomas, pero lo fui dominando, de modo tal que yo podía leer en cualquier idioma, por lo menos pude trabajar con eso, sin preocuparme ya de hablar bien. El alemán me sirvió mucho para orientarme en esta etapa, después fue el francés que yo no he dominado del todo, no lo hablo fluentemente, pero sí lo leo con facilidad. He estudiado el campo de la literatura comparada, en lo que los franceses y los alemanes han hecho mucho progreso, pero con literatura en castellano no se había tratado. Había leído a Riva-Agüero, en un trabajo que tiene sobre las influencias imitativas en la literatura peruana, donde habla del influjo preponderante de la literatura francesa, que es muy importante; de la literatura inglesa dijo que había algún influjo, pero que no había ninguno de la literatura alemana. Esto me preocupo y entonces fui investigando en fuentes peruanas y me encontré con que había un cúmulo de material, de traducciones, por ejemplo, o de aprecilaciones de crittca peruanasobre literatura alemana, imitaciones, etc. Comencé a reunicun-materiel de trabajo increíble, frente a una afirmación tan temeraria de Riva-Agüero, a quien se podía considerar un maestro, y entonces después de investigar el tema pude escribir todo un libro sobre autores germanos estudiados en el Perú, en el que hacía mérito de gente que había estudiado alemán, que había leído en alemán o se había ocupado de cuestiones alemanas, como González Prada, o como Juan de Arona, y otros, que juzgaban la cultura alemana a través de lo francés también, y pude contestar con un libro la frase negativa de Riva-Agüero. Eso ya me llevó a seguir estudiando el impacto de las letras inglesas, las letras italianas, las norteamericanas, las portuguesas, en sendos volúmenes. Hoy sigo trabajando en eso también, porque dentro de la literatura comparada cabe estudiar los viajeros, eso tampoco se había estudiado de una forma comprensiva, todo lo que hay de viajeros sobre el Perú, en el Perú o sobre el Perú. Porras había tratado no poco esa materia en sus fuentes sobre literatura peruana, que pueden verse en ese capítulo que se llama Fuentes de la literatura, pero no era un panorama completo. Yo me he preocupado de ir estudiando a los viajeros progresivamente y he publicado hace poco un libro que se llama Viajes y viajeros extranjeros por el Perí. 


\section{¿Cuándo se comienza a enseñar literatura peruana acá en la Universidad?}

En realidad, bueno, literatura peruana en la Universidad se inicia con Luis Alberto Sánchez. Riva-Agüero había escrito una tesis, Carácter de la literatura del Perí independiente, en 1905, pero no había una cátedra de literatura peruana propiamente, no estaba muy bien trabajado ese aspecto. Se consideraba que la literatura peruana era un apéndice de la literatura española, que la literatura peruana correspondía a una literatura provincial española, una cosa así. Pero ya a partir de Sánchez, que escribió un primer tratado sobre literatura peruana, un examen más detenido y ya más elaborado, puede decirse que comienza el estudio de la literatura peruana en una forma ya monográfica, formal y como una literatura autónoma, que no es un apéndice de la literatura española.

¿Usted en sus cursos, por ejemplo, dictaba estilística, o no dictaba ese tipo de cursos?

Yo dictaba el curso de Teoría literaria. Y en eso naturalmente estaba el estudio de todos los métodos para estudiar la literatura. Empecé en la Universidad reemplazando a Luis Fabio Xammar, que se murio repentinamente en un accidente de aviación el año 47, y entonces me hice cargo del curso de Literatura universal. $\mathrm{Al}$ poco tiempo vacó la cátedra de un curso de Literatura preceptiva, también con un antiguo criterio đe la preceptiva tradicional. Ese curso lo había dictado, con el título de «Literatura general», Alcides Spelucín, el poeta trujillano, pero fue destertado potsus aleas políticas en 9948 , y dejó vacante el

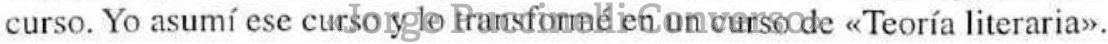

Doctor, hay una curiosidad que yo tenía. No sé si usted ha notado que los críticos de la generación anterior a la suy a o las anteriores a la suya, estoy pensando en Riva-Agüero, Sänchez, el mismo Mariátegui, eran personas muy involucradas en la política, pero en cambio los de la generación suya ya no están tan involucrados en la vida política. No sé si usted habrá reparado en este hecho.

Bueno, sí. Mariátegui entró un poco lateralmente a la literatura, porque lo que le preocupaba era el problema social y el problema socio-económico, el proceso integral que está estudiado en los 7 ensayos. El entró a la literatura un poco tangencialmente, con un criterio nuevo, de recoger las grandes corrientes sociales que repercuten en el devenir literario. Pero Sánchez no comenzó con criterio político. Sánchez comenzó a estudiar la literatura peruana como algo aparte de lo político. El se fue vinculando a lo político después. Pero su primer impulso de estudiar la literatura peruana fue un tanto errático. Nosotros, mi generación, 
ya entró a estudiar la literatura peruana como un fenómeno incependiente, considerando la evolución social, pero no estableciendo la deperdencia de lo literario hacia lo social.

¿Qué opinión tiene usted de la influencia tan grande que ha tenido el doctor Sánchez? ¿Tal vez él habría significado, sobre todo estoy pensando después de los años treinta, una especie de permanencia de los métodos tradicionales?

El tuvo un primer impulso de escribir un tratado literario de acuerdo con diversos criterios literarios y estéticos imperantes en el siglo XIX, pero que, como le digo, no tenían que ver con lo social. En Sánchez hay mucho de elemento historicista y eso se ve en los primeros tomos editados. Habría que estudiar su evolución analizando los textos de las 5 o 6 ediciones de su obra. Después él ha tratado de completar su tratado de literatura en una forma un poco apresurada, y entonces abandonó los criterios con-los cuales había entrado a estudiar el derrotero espiritual del Perú a través de su literatura. Ya al final como que se olvidó, como que le molestaba el sujetarse a un criterio preeśtablecido, y más bien ya hizo una historia literaria sin método ni coherencia, y' así termina hasta tratar el fenómeno actual, en el proceso de la literatura.

Lo que usted decía me parece interesante. Yo tengo la misma impresión que usted, o sea que Sánchez es muty descuidado por momentos No sé si usted ha reparado, en mi libro le hago una serie de críticas, porque él tiene muchos crrores, de datos inclisble poute pareceque et ha Doscoteja, o hay descuido,

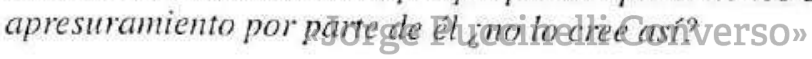

El debió haber hecho una especie de trabajo de seminario. Claro que no lo favoreció el hecho de que estuvo deportado mucho tiempo, interrumpía sus estancias en el país en varias oportunidades, por razones políticas. Pero él nunca tuvo una vocación para trabajar esto de una forma planificada y en equipo, algo indispensable en un estudio integral de una literatura. Eso le faltó. El trataba de seguir en un comienzo las huellas de La literatura argentina, de Ricardo Rojas. Esa fue su primera intención, hacer algo semejante a lo que había hecho Rojas. Pero Rojas trabajó en equipo y trabajó muy bien, con un criterio que le permitió hacer mucho más, una obra más grande, una historia literaria tal vez demasiado extensa, al punto que Borges llegó a decir alguna vez que Rojas había escrito una historia literaria que era más grande que la literatura argentina misma.

Pareciera que Sánchez ha logrado un prestigio excesivo, en parte tal vez debido a razones políticas. 
Bueno, a razones políticas y por una razón natural, pues en realidad no había otra historia, no se había hecho otro intento semejante. Todo lo que se había hecho no tenía la dimensión ni calidad semejante a lo que había abarcado Sánchez, y claro, como no había otro intento. Pero Sánchez es mal consejero para el investigador que se apoya en él, porque es muy inexacto e impreciso en sus datos, eso es evidente, y él nunca ha querido trabajar en equipo, en que los errores saltan inmediatamente y se pueden corregir. En una oportunidad, cuando estaba en vísperas de sacar una segunda o tercera edición de su Literatura peruana, una noche que estábamos con José Jiménez Borja y Sánchez, le sugerimos a Sánchez que nosotros podíamos, amigablemente, ayudarlo en hacer una revisión del texto para corregir ciertos errores que eran muy notables. Sí, dijo Sánchez, voy a tratar de hacerlo, pero nos cambió la conversación, y no aceptó la propuesta.

¿Cree usted que intentos posteriores de btros autores han caido en las mismas limitaciones?

Bueno, hay otros intentos que se han hecho, de resumir el conjunto de la literatura peruana a través de cursos universitarios como el de Tamayo Vargas, por ejemplo, que también contiene algunas deficiencias, en sus primeras ediciones. Yo lo ayudé mucho a Tamayo en corregir y él de buena voluntad aceptó, se logró así en pruebas corregir algunos equívocos, pero siempre quedaban muchas otras cosas por examinar detenidamente y confrontarlas.

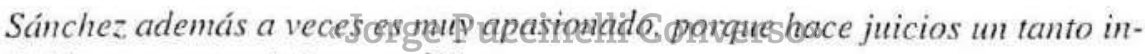
fluidos por sus opiniones políticas...

Bueno, en la última parte sí, en los últimos tomos hay mucho de eso. Hay opiniones políticas que le sirven a él para incluir en el proceso de la literatura peruana a una serie de nombres de gente que son sus amigos o sus copartidarios políticos, pero que no tienen ninguna validez en el campo literario, son extraños completamente. Inclusive tiene alguna antología de la poesía peruana editada en Chile, en que figuran casi todos los emigrados apristas que estaban en Chile. Sánchez no es riguroso en esas selecciones, y tampoco es riguroso en sus juicios en los últimos años, y tampoco en sus Memorias. Emite juicios muy a la ligera, un poco sobre la máquina y con poco respeto por la verdad. Lo que lo perjudica a Sánchez es su facilidad y superficialidad periodística, gracias a una memoria fácil que le es característica.

Yendo a otra cosa, doctor; pareciera que en los años veinte había un ambiente cultural muy movido acá en el Perí, atento a las novedades de fuera, y un poco 
que después eso ya no fue tan movido, en los años 30 o 40, parece que el ambiente peruano fuera menos intenso.

Los años 20, entre el 20 y 30 , fue una década de gran intensidad, con unas publicaciones pequeñas, pero muy reveladoras de una gran inquietud, sobre todo fue la época del indigenismo. Se observaba sobre todo en el surgimiento que entonces se opera de las provincias a la vida espiritual del Perú. Antes la provincia no contaba para nada, todo era Lima, pero a partir del año 20 , los provincianos tratan de afirmarse y entonces afluyen aquí a Lima o se forman focos de actividad literaria en Puno, en Cuzco, en Arequipa, en Trujillo, en Piura, hasta en Iquitos, hay actividad en las provincias. Eso es un fenómeno interesante porque no se había producido antes en el Perú. Eso lo había vislumbrado ya Valdelomar, cuando hace sus viajes por el Perú, a fines de la década anterior, el año 18, en que va a ponerse en contacto con los grupos literarios, y a levantar el espíritu de las provincias, dando conferencias y reuniéndose con las gentes intelectuales de los centros provinciales, pero eso sobre todo se desarolla mucho entre los años 20 y 30 , fue un fenómeno muy positivo.

\section{¿Por qué cree que cambió desptués eso?}

Bueno, cambiaron las circunstancias. Probablemente proseperó la idea de que el Perú no era Lima, y comenzóła migración de provincianos a Lima, y Lima fue un poco perdiendo su importancia, y surgieron centros de actividad intelectual y periódicos importantểétArequị̂a, en etcuzes, en Puno, en Trujillo,

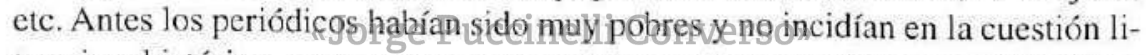
teraria o histórica, y por entonces comenzaron a tener suplementos literarios o históricos, en provincias sobre todo, y eso naturalmente fue positivo, en ese desarrollo de la vida espiritual del país, en esa década crucial, hasta el año 30 , en que se libró una batalla en pro de las ideas sociales.

¿Usted cree que de repente, justamente las dictaduras que vinieron después también pudieron haber influido en que cambie el ambiente cultural?

Por supuesto. El gobierno de Sánchez Cerro, de Benavides, revelan ese fenómeno. Porque después de esa década tan intensa del año 30 vino una década oscura, totalmente oscura, es como entrar en un páramo cultural, el que se observa en la década del 30 al 40.

¿Y ustedes sentian eso en la vida cultural?

Nosotros lo sentimos en carne propia. Esa fue la década en la cual se clausuraron las universidades en el Perú, y se paralizó prácticamente la vida espiritual 
del Perú. En el año 32 entramos en un túnel, del cual no salimos hasta el año 40.

\section{¿Las revistas dejaban de salir?}

El intelectual no tenía donde dar una conferencia, ni donde publicar un artículo. No habían revistas, no existían galerías de pintura, ni salas de concierto, ni sociedades literarias, ni organismos literarios, y las universidades clausuradas. En ese momento la clausura de la universidad significaba la parálisis de la vida intelectual del Perú. Hoy día hay otros ambientes, se han diversificado, pero en ese momento sí, fue una etapa dificilísima, porque fue causa de que mucha gente abandonase sus inquietudes intelectuales, para dedicarse a otras actividades, para vivir en cualquier otra forma. No tenía usted donde publicar, no tenía donde encontrarse con gente intelectual, a causa de la persecución política, en general no se conocía la libertad.

No hubo ninguna revista importante en esa etapa ¿no?

Nada. Las revistas que salían antes se clausuraron. Todo terminó prácticamente el año 31 , porque el año 30 había cesado Amauta, el año 32 prácticamente se paralizó el Mercurio Peruano, y comenzó a salir eventualmente. Curiosamente, la única institución intelectual seudointelectual, que subsistió fue «Entre nous», que era una institución en la cual dieron algunas conferencias RivaAgüero y sus amigos, $\$$ inadå måse Elambienteentectegtual se hizo deplorable, y dominaba una estreçhezde eriterioincréble Recuerdo que en el año 33, al celebrarse el centenario de Palma, Riva-Agüero se vio obligado, como entonces era Director de la Academia de la Lengua, se vio obligado a organizar un ciclo de conferencias en «Entre nous», porque era lo único que existía activo. Fue clamoroso el caso de uno de los que fue invitado a dar una conferencia, que fue Jorge Guillermo Leguía, un historiador de la generación del 19, la de Sánchez y de Basadre. En su conferencia sobre Palma, llegó a la conclusión de que nunca Palma fue alumno de la Universidad, o sea del Convictorio de San Carlos. Esto les cayó en una forma tremendamente impactante a algunos amigos de Palma y familiares suyos. La conferencia que dio Jorge Guillermo Leguía fue excluida del volumen que se dedicó a recoger las conferencias en honor de Palma con motivo de su centenario, por disposición de Riva-Agüero, quien tenía una fuerza tremenda en ese momento para decidir las cosas, y se cometió ese atropello contra la libertad de opinión. Yo, en otra ocasión, comencé a dar una serie de charlas sobre poetas peruanos por Radio Nacional del Perú, pero cuando supo el Presidente Benavides que iba a tratar de la poesía de 
González Prada, ordenó cancelar las charlas.

¿Y cuándo volvió a mejorar la atmósfera intelectual en el Perú?

La atmósfera cambió un poco por la acción de ciertas gentes que se dieron cuenta de que se vivía un ambiente completamente absurdo en esos momentos. Carlos Concha, Alberto Ulloa Sotomayor, Víctor Andrés Belaunde y algunos otros amigos de Benavides, lo convencieron de que debía hacer una apertura y cambiar un poco el ambiente, por una razón de decoro nacional, porque estaba muy próxima a celebrarse en Lima la Octava Conferencia Internacional Americana, o Conferencia Panamericana, pues vendrían representantes de todos los países americanos y algunos intelectuales del continente. En esa conferencia creo que intervino su padre en alguna forma, en el año $36 \ldots$

No, entonces era muy joven todavía. De repente usted está pensando en mi tío abuelo, que también era diplomático.

¿Quién era?

Enrique García-Bedoya.

Enrique García-Bedoya. Yo lo he conocido. Aquí en Barranco vivía, a cincuenta metros de mi casa. Yo viví mucho tiempo ahí en la avenida San Martín. Bueno y estos amigos conyencieron a Benavides de que había que preparar el ambiente, porque iba a cetebrarse la Conferencia Panamericana, iban a confluir aquí, como efectivametpe confluyeron, diplomaticos s $y$ periodistas. Yo fui secretario de una de las comisiones, como empleado del Ministerio de Relaciones Exteriores. Entonces para propiciar un cambio se creó la Orquesta Sinfónica Nacional, el año 38; el año 38 se fundó la Asociación Nacional de Escritores y Artistas, también, se creó la Asociación de Artistas Aficionados para el desarrollo del teatro, se creó un institución literaria que ofrecía conferencias todas las semanas, «Insula» de Miraflores, se creó una serie de organizaciones nuevas, surgieron librerías como la Librería Internacional, y entonces se comenzó a respirar un poco mejor, porque entonces se organizaron conferencias y exposiciones de pintura y conciertos y actividad de teatro, no a cargo de esos actores acartonados antiguos, tipo Rebolledo, etc., sino teatro a cargo de actores aficionados, con nueva inquietud, con una forma nueva, distinta, de actuar en el teatro. Eso significó ya el cambio. Eso fue al final de la década del 30, o sea el 38, prácticamente 39 . Se editó el 38 también, el gobierno auspició la edición de una colección de la literatura peruana, a cargo de Ventura García Calderón, ante quien no obstante, pudo todavía ejercer su censura, para modificar algún crite- 
rio, el propio gobierno de Benavides, que impidió que en esa colección figurara González Prada como prosador, simplemente lo pusieron como un poeta de los tantos, y se olvidaron de José María Eguren. En el año 38, Ventura García Calderón se olvidó de Eguren y también de Vallejo. Eguren pertenecía a la generación de Riva-Agüero, pero esa generación no lo reconoció, y él tuvo que refugiarse en la generación siguiente, que fue la que lo acogió, con Valdelomar y con Mariátegui. Riva-Agüero lo viene a reconocer a Eguren como poeta cuando tiene que pronunciar un discurso, a nombre de la Academia, en el sepelio de Eguren el año 42. Sólo lo apreciaba como persona «de buena familia limeña».

Claro, porque hasta ahi ellos siempre reivindicaban más bien a José Gálvez como poeta.

Para ellos valían José Gálvez y José Santos Chocano, y ahí punto. Todos ellos eran chocanescos, y el que no era como Chocano no era poeta. Nosotros reaccionamos precisamente contra eso y exaltamos a Eguren y Vallejo.

¿Y el periodismo, doctor? ¿Quienes eran los criticos famosos en esa época? ¿O no habia crítica periodística tampoco?

No había crítica periodística porque los periódicos no tenían suplementos literarios. La crítica periodística era por lo general de impresiones personales. Por ejemplo, Luis Varela y Orbegoso (Clovis), que era el crítico oficial de El Comercio, el único que habläba decesteccasuntos, y que pedia consagrar a un poeta en las crónicas casi diąrjas gue escribípẹn El Gpmencia, Luego surgió en ese mismo periódico Aurelio Miró Quesada Sosa, quien daba a conocer nuevos valores europeos como Joyce y también acogió a Vallejo.

Algunos años antes, el crítico más connotado había sido Clemente Palma ¿no?

Clemente Palma había sido un buen escritor antes de la época de Leguía, porque después se convirtió en un periodista leguiísta, que apoyaba al gobierno. Pero se equivocó tremendamente Clemente Palma. No entendió a Eguren, ni menos a Vallejo, y a los dos les tomó el pelo y dijo barbaridades humorísticas sobre el uno y sobre el otro.

¿Y este Clovis también era por el estilo?

Clovis también era por el estilo, pero también un fino cronista. Y no había más crítica. Algunas veces escribía el que prologó el segundo libro de Eguren, $\mathrm{La}$ canción de las figuras, que fue Enrique Carrillo «Cabotín», quien además era 
un cronista muy ágil y que tenía buen sentido crítico. Ese prólogo está bien hecho. Es uno de los pocos comentarios que en su época se escribieron sobre Eguren, antes de que se le reconociera gracias a los aportes fundamentalmente de Pedro S. Zulen y de Mariátegui después.

¿O sea que no hemos tenido buena crítica periodística tampoco acá en el Perú?

Se estilaba una crítica muy ligera. Valdelomar hacía un poco de crítica también, pero era más bien un cronista, como en su primera época también Mariátegui no era sino un cronista de periódico, lo que llamó el propio Mariátegui su «edad de piedra». Los comienzos de la crónica periodística dejaron algunos aportes aprovechables por los investigadores de hoy. Ahora la crítica tiene un carácter de investigación universitaria y de análisis conceptual.
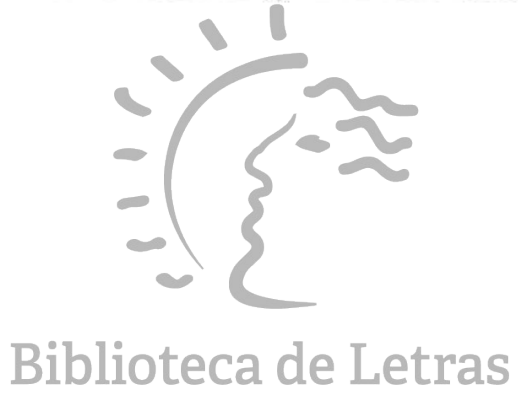
"Jorge Puccinelli Converso" 